\title{
Polimorfismo de los genes PPAR-y e IL-6 -174G/C y su asociación con obesidad, sobrepeso, grasa corporal y el riesgo de enfermedad cardiovascular, en una población adulta de Lima
}

Doris Huerta, Oscar Acosta, Jaime Pajuelo

Centro de Investigación de Bioquímica y Nutrición, Facultad de Medicina, UNMSM

Objetivos: Determinar las frecuencias genotípicas y alélicas de genes PPPAR- $\gamma$ e IL-6 -174G/C en población de Lima y establecer asociación del polimorfismo de los genes PPAR- $\gamma$ y de la II-6 -174G/C con el sobrepeso, obesidad y factores de riesgo cardiovascular.

Diseño: Descriptivo, relacional, tipo casos-control.

Institución: Centro de Investigación de Bioquímica y Nutrición, Facultad de Medicina, UNMSM.

Participantes: Limeños con y sin sobrepeso-obesidad.

Intervenciones: A una muestra poblacional de Lima, de 94 personas, 40 control y 50 con sobrepeso-obesidad, se realizó extracción del ADN genómico, análisis del polimorfismo Pro12Ala PPARgamma-2 y -174G/C IL6, mediante PCR/RFLP, digestión con enzima de restricción Nlalll y SfaNl, respectivamente, detección por electroforesis en agarosa $2 \%$ y tinción con bromuro de etidio.

Principales medidas de resultados: Frecuencias de los genotipos (CC, CG y GG) y alelos (C y G) de los genes PPAR gamma-2 y -174G/C IL6, en ambos grupos.

Resultados: Las distribuciones de los genotipos en ambos grupos estuvieron de acuerdo a la hipótesis del equilibrio de Hardy-Weinberg, para ambos genes. No hubo asociación entre los genotipos ni entre los alelos de ambos genes con el sobrepeso-obesidad, en la muestra estudiada.

Conclusiones: Los resultados no demostraron asociación de los genes PPAR gamma2 e IL6-174 con el sobrepesoobesidad, pero se proyecta ampliar el tamaño de la muestras, controlando las variables clínicas e incluir otros genes.

Palabras clave: Polimorfismo genético, obesidad, sobrepeso, grasa ectópica, enfermedad cardiovascular.

\section{Ribotipificación de Escherichia coli y Klebsiella pneumoniae productoras de BLEEs, aisladas de pacientes hospitalizados y de la comunidad del Instituto Nacional de Salud del Niño}

\author{
Mario Monteghirfo, Jaime Barrón, María Rodrigo, Rodolfo Velazco \\ Centro de Investigación de Bioquímica y Nutrición, Facultad de Medicina, UNMSM; Servicio de Microbiología Instituto Nacional de Salud del
}

Objetivos: Investigar la epidemiología molecular y clínica de E. coli y K. pneumoniae productoras de beta lactamasas de espectro extendido (BLEE), de muestras procedentes de pacientes hospitalizados y de pacientes de la comunidad.

Diseño: Descriptivo.

Institución: Centro de Investigación de Bioquímica y Nutrición, Facultad de Medicina, UNMSM; Servicio de Microbiología Instituto Nacional de Salud del Niño.

Participantes: Muestra poblacional de Lima, de 31 personas.

Intervenciones: Extracción de ADN genómico de E. coli, amplificación de la región espaciadora intergénica entre los genes $16 \mathrm{~S}$ y $23 \mathrm{~S}$ con primers $1406 \mathrm{f}$ y $23 \mathrm{Sr}$, detección por electroforesis en agarosa al 1,5\% y tinción con bromuro de etidio. Se realizó el análisis de los patrones de huella de ADN mediante análisis del espaciador intergénico ribosomal (RISA). Para el agrupamiento jerárquico de los patrones se usó el algoritmo de agrupamiento UPGMA

Principales medidas de resultados: Diferencias en los patrones RISA de E. coli.

Resultados: En las muestras analizadas, se detectó diferencias en los patrones RISA. Empleando el coeficiente de similitud de Jaccard, se formó agrupaciones con seis variables.

Conclusiones: El nivel de resolución del análisis RISA fue lo suficientemente sensible para detectar diferencias entre las cepas de E. coli.

Palabras clave: E. coli, ribotipificación, PCR, RISA. 